\title{
Nanoparticle-Supported Molecular Polymerization Catalysts
}

\author{
Abderrahmane Amgoune, Marina Krumova, and Stefan Mecking* \\ Chair of Chemical Materials Science, Department of Chemistry, University of Konstanz, \\ Universitätsstrasse 10, D-78457 Konstanz, Germany
}

\begin{abstract}
Homogeneous molecular catalysts are immobilzed in a well-defined fashion on individual silica nanoparticles with a narrow particle size distribution by covalent attachment. This synthetic methodology is demonstrated with modified salicylaldiminato-substituted titanium(IV) complexes incorporating a trimethoxysilaneterminated linker: dichloro-bis $\left[\kappa^{2}-N, O-6-(3\right.$-(trimethoxysilyl)propoxyphenylimino)-2-tert-butyl-phenolato]titanium(IV) (3) and dichlorobis [ $\kappa^{2}-N, O-6$-(4-(trimethoxysilyl)propoxy-2,3,5,6-tetrafluorophenylimino)-2-tertbutylphenolato]titanium(IV) (4). $\mathbf{3}$ and $\mathbf{4}$ were bound covalently to silica nanoparticles via direct condensation of the alkoxysilane with residual silanol groups on the lipophilically modified particle surface. The resulting nonaggregated individual silica nanoparticles (ca. $50 \mathrm{~nm}$ diameter) with catalyst bound to the outer surface have been characterized by CP-MAS NMR, FT-IR spectroscopy and by electron microscopy (TEM, ESI). These supported catalysts exhibit single site characteristics for the polymerization of ethylene, affording ultra high molecular weight polyethylene. Polymer particles with a uniform spherical morphology and a particle size in the submicron regime are formed. TEM analyses of cross-sections of single particles formed at different polymerization times revealed a complete fragmentation of the nanoparticle support to fragments of ca. $10 \mathrm{~nm}$ size homogeneously distributed in the polymer matrix.
\end{abstract}

\section{Introduction}

Mononuclear transition-metal complexes (metallocenes and postmetallocenes) have achieved an amazing level of performance for the polymerization of 1-olefins in terms of activity, control of polymer molecular weight and microstructure. ${ }^{1}$ They also greatly contributed to the mechanistic comprehension of the polymerization process. However, in the industrially applied gas-phase and slurry processes in which the polymer is insoluble in the reaction media, solid catalyst particles are required to prevent reactor fouling and other undesired phenomena. Therefore, immobilization of homogeneous catalysts on insoluble supports has been studied intensely.,3 Amorphous silica is most commonly used as a support due to its high surface area, good mechanical properties, and silanol functionalities to anchor the catalyst. $^{2-4}$ Two different general approaches have been developed to immobilize the catalyst on silica, via ionic ${ }^{3,5}$ or covalent ${ }^{6}$ interactions, but they generally result in multisite and complex surface species which are difficult to study. ${ }^{2,3}$ Mechanistic insights on the catalyst precursors interaction with the surface and on the reactivity of the heterogeneous catalysts have been gained using silsesquioxane as a homogeneous model systems for silica surface silanols. ${ }^{4,7}$ Recent efforts have been focused on the preparation of well-defined supported organometallic catalysts for various applications, ${ }^{8}$ but efficient synthetic methods for the preparation of well-defined silica-supported polymerization catalyst are rare., ${ }^{2,9}$

Control of the morphology of the polyolefin particles is the major motivation for the supporting of polymerization active metal complexes. At the early stage of the polymerization, the initial macroscopic, porous silica particles fragment, more or less efficiently depending on the nature of the support. From the submicron particles thus formed, polymer particle growth occurs. The fragmentation is a limiting step which has a strong influence on the activity of the catalyst and on the final particle morphology. ${ }^{3,10}$ For example, due to heterogeneity in rigidity and/or porosity of the support, fragmentation of silica-supported Ziegler or metallocene catalysts may occur to a different extent

\footnotetext{
* Corresponding author. E-mail: stefan.mecking@uni-konstanz.de.
}

locally, resulting in catalyst fragments of a range of sizes and shapes. ${ }^{11}$ A low catalyst concentration on parts of the support would even cause incomplete fragmentation, leaving large particles of silica within the polymer.

In this context, the preparation of well-defined and uniformly structured supported catalyst systems which enable a high level of structural characterization and the formation of specific and uniform polymer morphology is of strong interest. Such a system could be provided by nonaggregated uniform silica nanoparticles, prepared from molecular precursors. Nonaggregated, individually dispersed silica nanoparticles (prepared from tetraethyl-orthosilicate by the Stöber-route) have been widely used as a starting material for the preparation of core-shell hybrid nanostructures or nanocomposites. ${ }^{12}$ Somewhat surprisingly, they have not been reported as a support for olefin polymerization catalysts despite offering attractive features: (i) they could allow for a well controlled immobilization process of polymerization catalysts with a high level of characterization, (ii) the homogeneity of the support in terms of porosity and morphology would considerably reduce complexity of the support and consequently of the fragmentation process (uniform particle fragments), and allow for controlled polymer particle growth, and (iii) rather small polymer particles $(<1 \mu \mathrm{m})$ could be accessible starting from nanoscale catalyst particles, which are e.g. of interest for the processing of ultrahigh molecular weight polyethylene.

Herein we report the well-defined immobilization of homogeneous molecular catalysts on individual silica nanoparticles with a narrow particle size distribution by covalent attachment. This synthetic methodology is demonstrated for efficient salicylaldiminato-substituted titanium(IV) complexes developed by Fujita, ${ }^{1 \mathrm{f}, 13}$ which polymerize ethylene to ultrahigh molecular weight polyethylene (UHMWPE). Polymer particles with uniform spherical shape result. The support-nanoparticles fragment at an early stage, the resulting silica fragments being distributed homogeneously in the polymer matrix.

\section{Results and Discussion}

Synthesis of Surface Modified Silica Nanoparticles. Spherical silica nanoparticles were prepared by the Stöber process, 
Scheme 1. Preparation of Modified Silica Nanoparticle Dispersed in Toluene

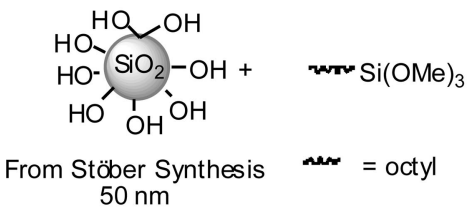

and modified in order to allow stabilization in hydrophobic solvents such as toluene. Silica particles with an average diameter of $50 \mathrm{~nm}$ and a narrow particle size distribution were obtained from tetraethylorthosilicate in ethanol/aqueous ammonia solution. ${ }^{14}$ These spherical particles were subsequently modified lipophilically by reaction of a part of the surface silanol groups with trimethoxy(octyl)silane (Scheme 1). ${ }^{15,16}$ This surface functionalization enables transfer of the particles into toluene as a dispersing medium via azeotropic distillation (for details cf. experimental section).

Excess organosilane and residual impurities were then removed by repeated centrifugation/ redispersion steps in toluene. At an appropriate excess amount of organosilane and reaction time, colloidally stable dispersions of partially modified nonaggregated silica nanoparticles in toluene are obtained. The silica particles can be dried under vacuum at $50{ }^{\circ} \mathrm{C}$ to afford a white powder which is easily redispersible in toluene, that is also under these conditions no significant interparticle condensation occurs. The resulting silica particles have a diameter of ca. $50 \mathrm{~nm}$, also the narrow particle size distribution is retained upon surface modification, as determined by dynamic light scattering (DLS) and transmission electron microscopy (TEM; cf. Figure 1). Grafting of the organosilane is evidenced by solid state CPMAS NMR and FT-IR spectroscopy, as well as elemental analysis (cf. Supporting Information). From the carbon content, the graft density of the octyl silane on the silica particles was found to be between 16 and $22 \mu \mathrm{mol}$ of silane per $\mathrm{m}^{2}$ of silica (corresponding to $9-13$ silane molecules per $\mathrm{nm}^{2}$ ). ${ }^{17} \mathrm{In}$ addition to characteristic signals of the octylsilane moieties, the FT-IR spectrum also indicates the desired presence of residual silanol
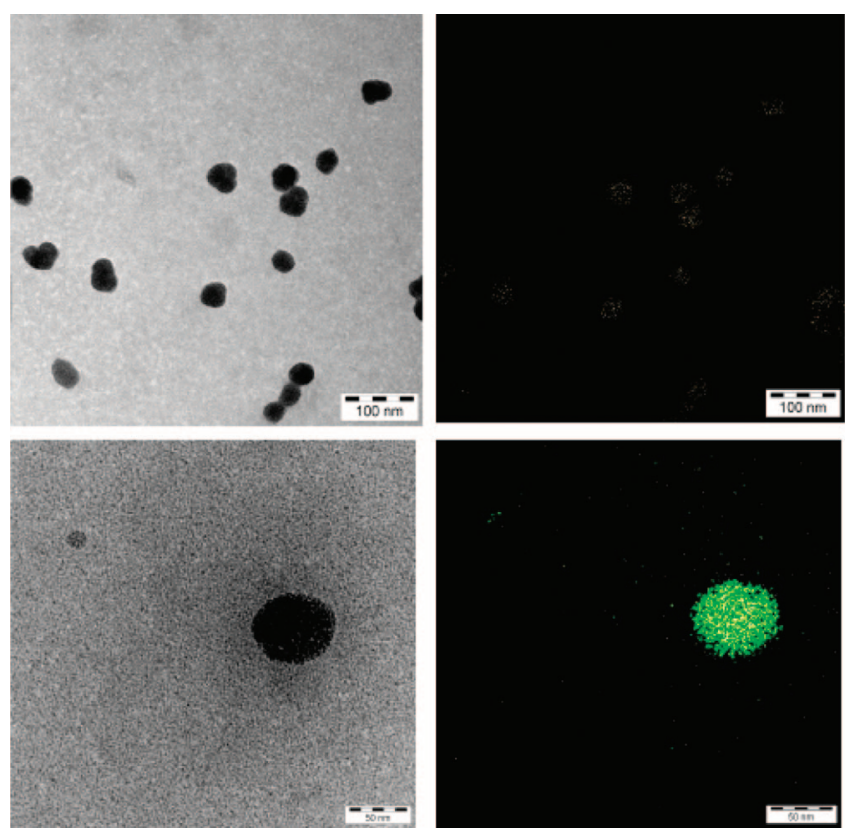

Figure 1. TEM image (upper left) and ESI at the energy loss of chloride (upper right, bright spots correspond to chloride on the particle surface) of complex-grafted silica nanoparticles (5). TEM image (lower left) and ESI at the energy loss of titanium (lower right) of complex-grafted silica nanoparticles $(\mathbf{6})$.

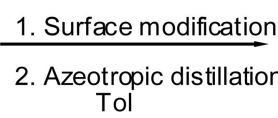

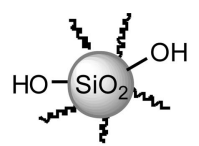

dispersion in dry toluene $55 \mathrm{~nm}$ groups on the silica surface (cf. Figure S1 in Supporting Information).

Syntheses and Characterization of Silica Nanoparticle Supported Catalysts. The supporting of salicylaldiminatosubstituted titanium(IV) complexes via interactions of MAO cocatalyst with pyridine-substituted polymer latex particles (ca. $180 \mathrm{~nm}$ ), and the preparation of UHMWPE with these supported catalysts has been reported recently. ${ }^{18}$ To enable covalent biniding of titanium complexes to silica nanoparticles via the residual silanol groups, a reactive siloxane linker was introduced in the salicylaldiminato ligand. The linker was introduced in a position rather remote to the metal center, in order of not deteriorating catalytic properties of the latter (Scheme 2).

The phenoxy-imine $\mathbf{1}$ was obtained in quantitative yield by the Schiff base condensation reaction of tert-butylsalicylaldehyde and 3-(trimethoxysilyl)propoxy-aniline in dry toluene (Scheme 2a). Salicylaldimine 2 , with a tetrafluorinated $N$-aryl moiety, was prepared by reaction of deprotonated tetrafluoro4-hydroxy-aniline with 3-chloropropyltrimethoxysilane in toluene/ DMSO, and subsequent condensation of the siloxane-functionalized aniline A formed with tert-butylsalicylaldehyde. The high reactivity of $\mathbf{A}$ towards water (which is liberated in the condensation reaction) resulted in some hydrolysis and condensation of the silylmethoxy groups to form a small portion of insoluble materials. ${ }^{19}$ However, after workup 2 could be isolated in $48 \%$ yield as a brownish oil.

Titanium complexes $\mathbf{3}$ and $\mathbf{4}$ were obtained in moderate to high yields as red-brown powders by reaction of two equivalents of $\mathbf{1}$ and 2, respectively with $\left[\mathrm{Ti}\left(\mathrm{O}^{\mathrm{i} P r}\right)_{2} \mathrm{Cl}_{2}\right]$ in THF (Scheme 3).

Immobilization on Silica Nanoparticles. Complexes $\mathbf{3}$ and 4, respectively, were covalently bound to the surface of silica nanoparticles by reaction of the trimethoxysilyl moieties in $\mathbf{3}$ and 4 with residual silanol groups on the silica nanoparticles surface (Scheme 4). Unreacted or self-condensed complex was removed from the particles by several centrifugation/redispersion steps in dry toluene, to afford nanoparticles $\mathbf{5}$ and $\mathbf{6}$ with covalently bound complexes. After drying under vacuum at 50 ${ }^{\circ} \mathrm{C}$ for $24 \mathrm{~h}, \mathbf{5}$ and $\mathbf{6}$ were obtained as yellow powders, which were stored in a glovebox.

As an alternative route, covalent binding of the free ligands $\mathbf{1}$ and $\mathbf{2}$, respectively, to silica nanoparticles and subsequent reaction with $\left[\mathrm{Ti}\left(\mathrm{O}^{\mathrm{i} P r}\right)_{2} \mathrm{Cl}_{2}\right]$ was studied. In all cases, polydisperse particle size distributions resulted due to the formation of agglomerates, as revealed by DLS and TEM analyses. Materials prepared via this route were therefore not studied further.

Characterization of Silica Nanoparticle-Bound Complexes. Dynamic light scattering (DLS) and TEM revealed unaggregated nanoparticles also after catalyst grafting (cf. Supporting Information, Figures S4 and S5). Binding of complexes on the surface of silica nanoparticles was confirmed by solid state NMR, FT-IR spectroscopy, elemental analysis and electron microscopy (TEM, ESI). Characteristic peaks of the complex were observed by FT-IR spectroscopy. In addition to the $\mathrm{C}-\mathrm{H}$ aliphatic stretch band at $2980 \mathrm{~cm}^{-1}$ originating from octyltrioxysilane moieties, bands at $1395 \mathrm{~cm}^{-1}\left(v\left(\mathrm{CH}_{3}\right)\right.$ tertbutyl) and $1630 \mathrm{~cm}^{-1}(v(C=\mathrm{N}))$ of the salicylaldiminato ligands 
Scheme 2. Preparation of Trimethoxysilyl-Substituted Salicylaldimines
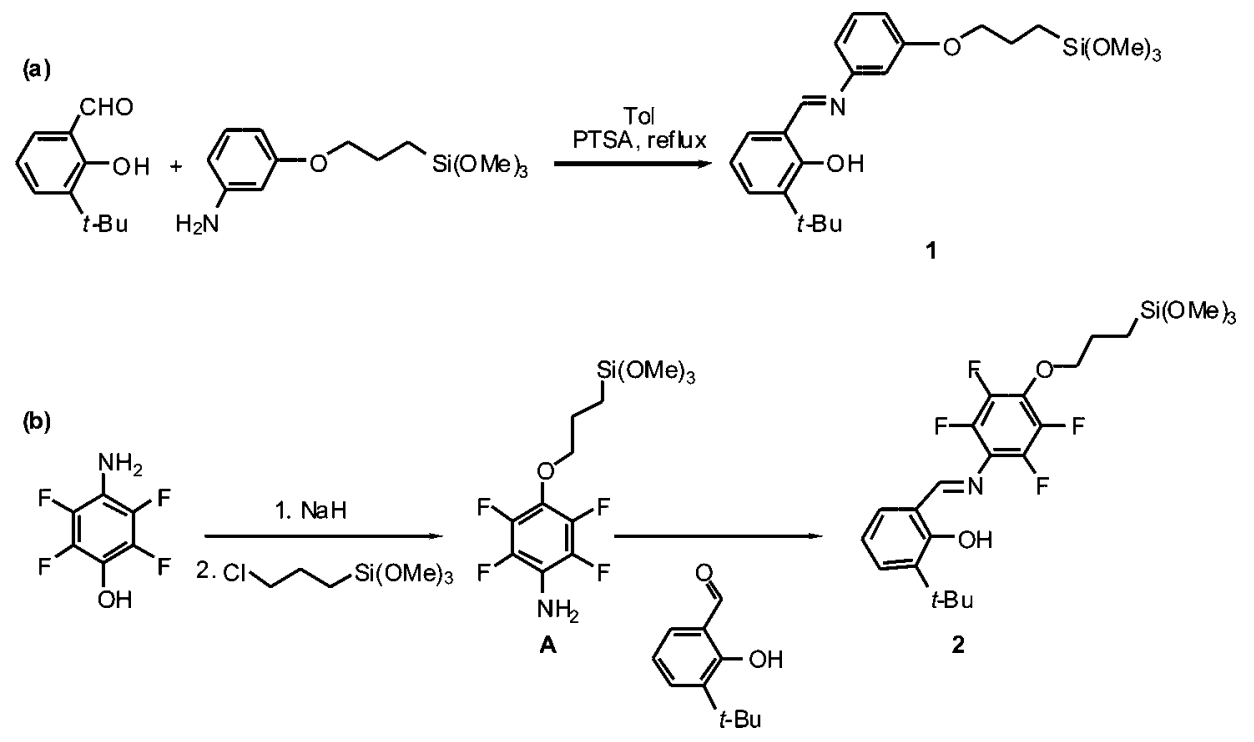

Scheme 3. Preparation of Trimethoxysilyl-Substituted Titanium Salicylaldiminato Complexes

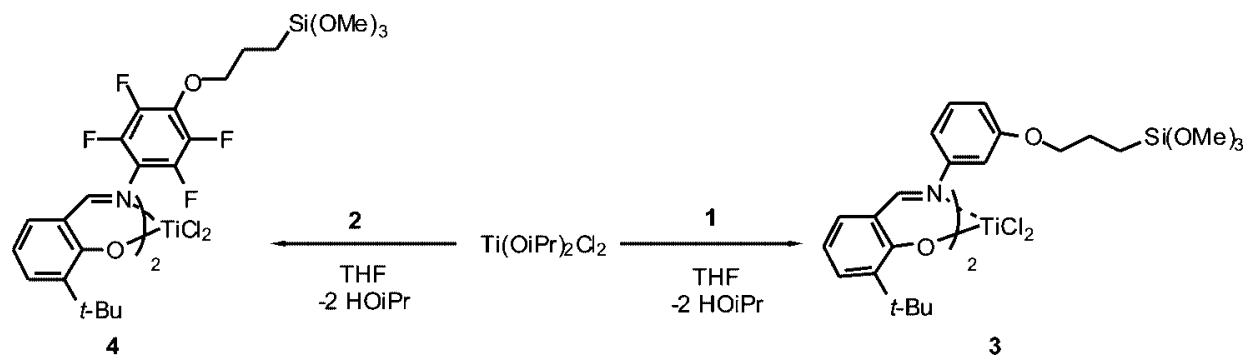

Scheme 4. Covalent Binding of Complexes 3 and 4 to Silica Nanoparticles

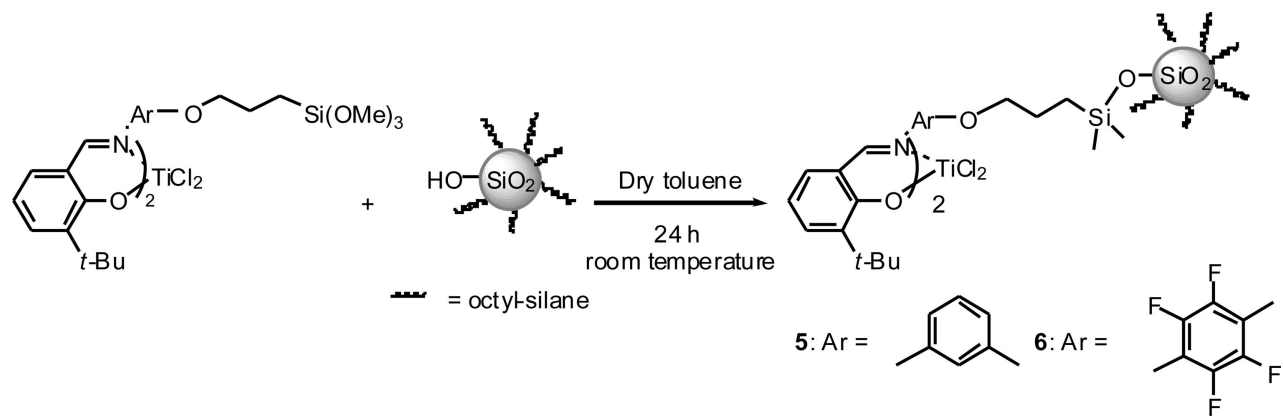

are observed. Solid state ${ }^{29} \mathrm{Si}$ and ${ }^{13} \mathrm{C}$ CP-MAS NMR spectroscopy also revealed the presence of surface bound octyltrioxysilane and catalyst. ${ }^{13} \mathrm{C}$ and ${ }^{1} \mathrm{H}$ NMR spectra exhibit signals from the surface-bound catalysts in the aromatic region (cf. Supporting Information). Elemental analysis of the nitrogen content qualitatively confirms the presence of the complex (cf. Table S1 in Supporting Information). Furthermore, the presence of titanium and chloride on the silica nanoparticle surface was probed by element specific imaging (ESI) via electron energy loss spectroscopy (EELS). TEM images of silica nanoparticles $\mathbf{5}$ and $\mathbf{6}$ and resolved element distribution images at the energy loss of chloride and titanium show the spherical shape of the monodisperse nanoparticles and also the presence of chloride and titanium distributed on the silica surface (Figure 1). These observations support that after the centrifugation/redispersion steps, catalysts remain grafted on the nanoparticle surface. In order to further confirm that the complex is covalently bound to the surface and not only physically adsorbed, a comparative experiment was carried out with a salicylaldiminato-substituted
titanium(IV) analogue of complex 4, but lacking the siloxane linker. The compound was reacted with octyl-modified silica under exactly the same conditions as employed for complexes $\mathbf{3}$ and 4, and unreacted complex was again removed from the silica particles by several centrifugation/redispersion steps in dry toluene. After drying under vacuum at $50{ }^{\circ} \mathrm{C}$ for $24 \mathrm{~h}$, a white powder was obtained. No evidence for the presence of the complex on the silica surface was found via electron energy loss spectroscopy (EELS) and elemental analysis (cf. Supporting Information Figure S7). Furthermore, in contrast to the silicasupported complexes $\mathbf{5}$ and $\mathbf{6}$, no catalytic activity towards ethylene was observed upon activation with MAO (vide infra).

Polymerization Studies. Ethylene polymerization with silica nanoparticle-supported catalyst precursors $\mathbf{5}$ and $\mathbf{6}$, and also the nonimmobilized complexes $\mathbf{3}$ and $\mathbf{4}$ for comparison was studied (Table 1). Supported catalysts were dispersed in toluene, and the dispersion was added to a toluene solution saturated with ethylene containing MAO as an activator in the polymerization 
Table 1. Polymerization Results ${ }^{a}$

\begin{tabular}{|c|c|c|c|c|c|c|c|}
\hline entry & catalyst & $\begin{array}{c}\mathrm{Ti} \\
\text { loading }^{b}\end{array}$ & $\begin{array}{l}\text { time } \\
(\min )\end{array}$ & $\mathrm{Al}: \mathrm{Ti}$ & activity $^{c}$ & $\begin{array}{c}\mathrm{M}_{n}{ }^{d} \\
\left(\mathrm{~g} \mathrm{~mol}^{-1}\right)\end{array}$ & $M_{\mathrm{w}} / M_{\mathrm{n}}$ \\
\hline $1^{e}$ & 3 & & 10 & 2500 & 1760 & $2.5 \times 10^{5}$ & 3.4 \\
\hline $2^{e}$ & 3 & & 30 & 1000 & 1000 & $5.6 \times 10^{5}$ & 2.3 \\
\hline 3 & $\mathbf{3}+$ silica & 320 & 30 & 1000 & 575 & $2.0 \times 10^{5}$ & 1.7 \\
\hline 4 & 5 & 67 & 60 & 1000 & 195 & $2.6 \times 10^{5}$ & 2.2 \\
\hline 5 & 5 & 67 & 120 & 1000 & 220 & $1.7 \times 10^{6}$ & 3.0 \\
\hline $5^{\prime}$ & 5 & 67 & 15 & 1000 & & n.d. & n.d. \\
\hline $5^{\prime \prime}$ & 5 & 67 & 30 & 1000 & & $3.7 \times 10^{5}$ & 2.0 \\
\hline $6^{e}$ & 4 & & 30 & 1000 & 4800 & $4.4 \times 10^{5}$ & 1.6 \\
\hline 7 & 6 & 42 & 60 & 1000 & 520 & $2.6 \times 10^{6}$ & 2.1 \\
\hline
\end{tabular}

a $200 \mathrm{~mL}$ of toluene, $T=50^{\circ} \mathrm{C}, 2$ bar ethylene pressure, MAO as a cocatalyst, $\mathrm{m}_{\text {silica }}=25 \mathrm{mg} .{ }^{b}$ in $\mu \mathrm{mol} \mathrm{g}-1$ of catalyst. ${ }^{c}$ in $\mathrm{kg}(\mathrm{PE}) \mathrm{mol}(\mathrm{Ti})^{-1}$ $\mathrm{h}^{-1} \mathrm{bar}^{-1}$ (for supported catalysts 5 and $\mathbf{6}$ referring to Ti content determined from $\mathrm{N}$ content found by elemental analysis. $\mathrm{N}$ content values are presented in the Supporting Informations). ${ }^{d}$ determined by GPC at $160{ }^{\circ} \mathrm{C}$, referenced to linear polyethylene standards. ${ }^{e}$ homogeneous catalysts.

reactor. Polymerizations were conducted at $50{ }^{\circ} \mathrm{C}$ and 2 atm ethylene pressure.

Supported catalysts 5 and $\mathbf{6}$ produce polyethylene with catalytic activities which are lower than those observed for the nonsupported analogues $\mathbf{3}$ and $\mathbf{4}$, respectively (entries 4, 7 vs $2,6)$. The activity of the supported catalyst 6 is higher compared to the activity of $\mathbf{5}$, the same trend is observed with nonsupported analogues $\mathbf{3}$ and $\mathbf{4}$ (entries 6 and 2), and was also reported for the homogeneous parent salicylaldiminato Ti catalysts. ${ }^{13,20} \mathrm{~A}$ decrease in activity for silica-supported complexes by comparison to the nonsupported analogues is generally observed. This may result from interactions of the silica surface with the (ionic) active species, and diffusion limitations of monomer through the formed polymer layer on the particle surface (cf. Scheme 5) to the active sites, which may also be less accessible by comparison to an (initially) homogeneous solution. Usually, this decrease amounts to an order of magnitude or more. ${ }^{6 \mathrm{~d}-\mathrm{g}}$ As also previously found for other immobilization processes on porous silica substrates, ${ }^{9}$ the efficient and controlled synthetic route used to prepare these silica nanoparticle-supported catalysts which affords isolated active sites is a possible explanation for their relatively high activity in ethylene polymerization. Increasing the ethylene pressure to 10 bar did not result in a higher activity of the supported catalysts. A study of the polymerization over time with the supported catalyst $\mathbf{5}$ shows the catalyst to be stable over prolonged reaction times (entry 5).
Polyethylenes obtained with the supported catalysts were not soluble in hot trichlorobenzene solution, and the PE could not be extracted from the silica nanoparticles even upon heating the solution to $130{ }^{\circ} \mathrm{C}$ for several hours. Etching with aqueous HF to remove the silica enabled the subsequent dissolution of the polymer in trichlorobenzene, for GPC analysis. By comparison, polymer obtained by polymerization with a nonimmobilized catalyst in the presence of added lipophilic silica nanoparticles afforded a polymer which could be dissolved easily without prior treatment with HF. These findings underline an intimate mixing and interaction of the (fragmented, vide infra) catalyst-functionalized nanoparticles with the polymer. GPC analysis reveal the polyethylenes formed to possess high to ultra high molecular weights, with molecular weight distributions indicative of single site behavior (Table 1).

DSC analyses show melting temperatures and enthalpies of fusion which correspond to highly linear and ultrahigh molecular weight PEs melting behavior. ${ }^{21}$ PEs obtained with supported catalysts exhibit high melting temperature $\left(141-146^{\circ} \mathrm{C}\right)$ and heats of fusion $\left(\Delta \mathrm{H}_{\mathrm{m}}=190-200 \mathrm{~J} / \mathrm{g}\right)$ in the first heating cycle, and these values are significantly reduced in the second heating cycle $\left(T_{\mathrm{m}}=137-139{ }^{\circ} \mathrm{C}, \Delta H_{\mathrm{m}}=149-169 \mathrm{~J} / \mathrm{g}\right)$. The large difference between crystallinities in the first and second heating cycle is due to chain entanglement in the melt hindering recrystallization.

Polymer morphologies were investigated by scanning electron microscopy (SEM). Polyethylene obtained with a nonsupported catalyst precursor (3) possesses fibrillar morphology as expected (Figure 2, left). ${ }^{22}$ By contrast, polymerization with nanoparticlesupported catalyst (5) afforded uniform spherical polymer particles (Figure 2, right). This is consistent with polymer chain growth from the nanoparticle surface. In a comparative polymerization experiment with nonsupported catalyst physically mixed with a dispersion of lipophilic silica nanoparticles (entry 3 in Table 1), a fibrillar morphology is obtained, with intact silica nanoparticles dispersed on the fibrils (Figure 2, center). Obviously, covalent binding of the catalyst to the nanoparticle support is a prerequisite for the aforementioned control of morphology. Conceivable leaching of the supported catalysts was probed by activation with MAO for several minutes, and subsequent centrifugation and separation of the supernatant solution. No catalytic activity of the supernatant was observed

\section{Scheme 5. Illustration of the Fragmentation Process}

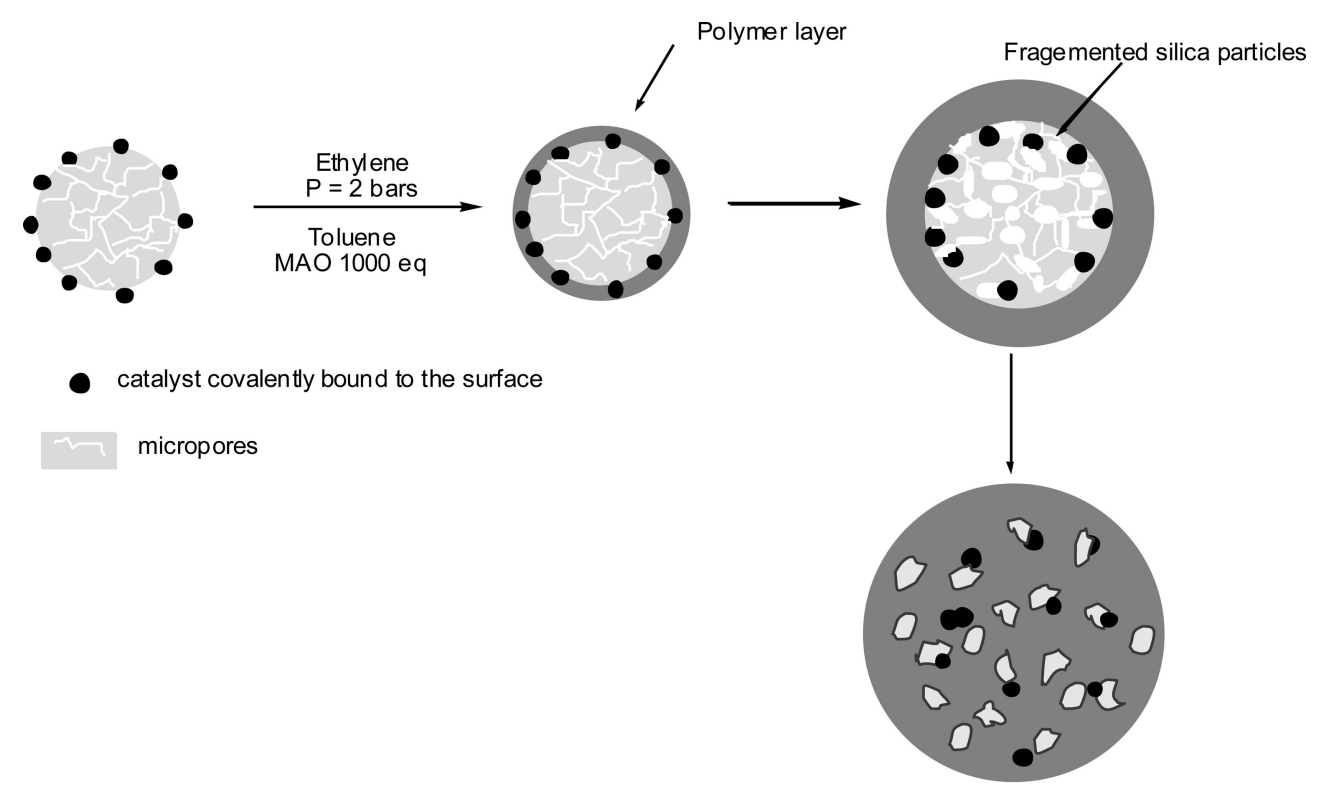

Polymer particle with small $(8-12 \mathrm{~nm})$ silica fragments 

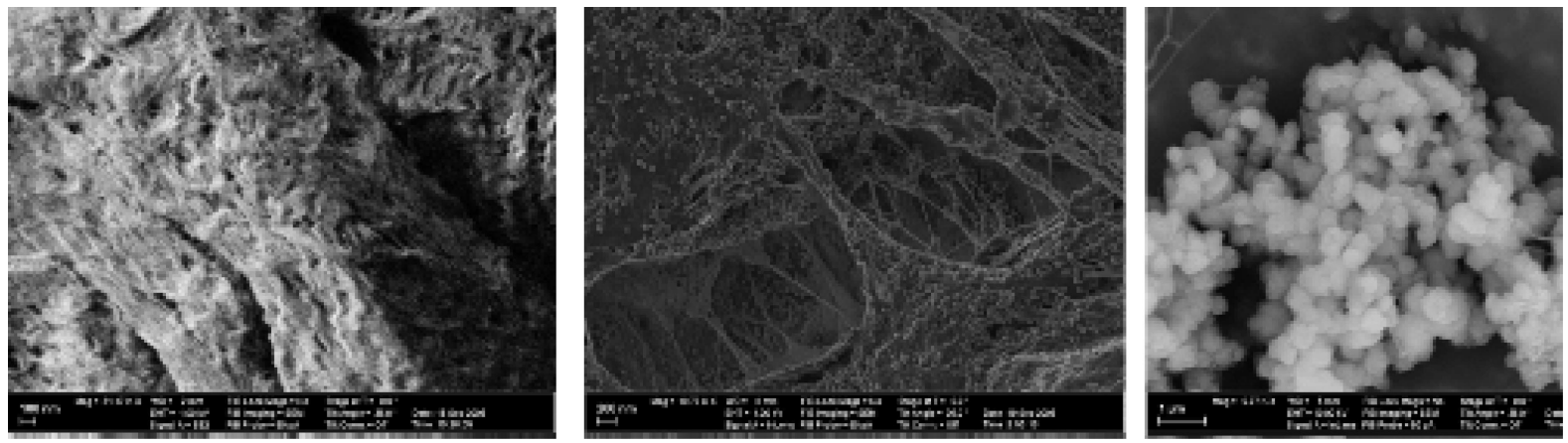

Figure 2. SEM images of polymer obtained with nonsupported catalyst (left), with a physical mixture of nonsupported catalyst and silica nanoparticle dispersion (center), and with silica nanoparticle-supported catalyst (right).

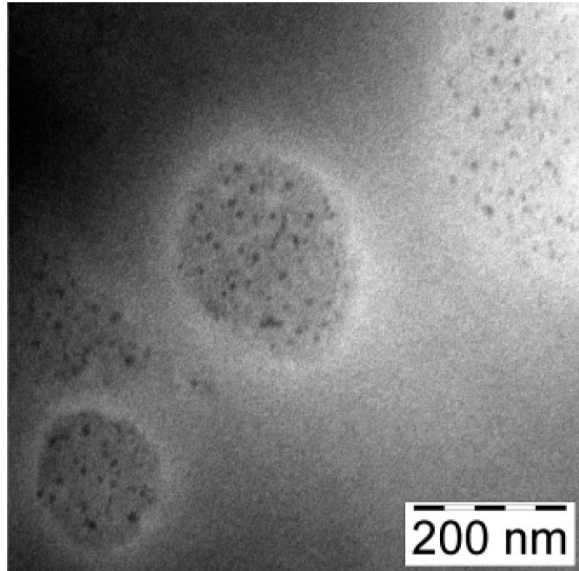

Figure 3. TEM image of a cross-section of polyethylene particles at $\Delta E=30 \mathrm{eV}$.

upon exposure to ethylene, indicating that leaching does not occur to any significant extent.

The internal structure of polymer particles was studied by TEM on thin cross-sections microtomed at room temperature from a sample (entry 5) embedded in Epofix resin. Silica nanoparticles are observed which are distributed homogeneously within the polyethylene particles (Figure 3). Surprisingly, these silica particles have a size of only ca. 8 to $12 \mathrm{~nm}$. No intact original particles are observed, indicating clearly that a fragmentation must have occurred.

Silica nanoparticles obtained from Stöber-synthesis are usually considered to be smooth, compact particles. ${ }^{12,14,16,23}$ However, surface area determinations by mercury porosimetry and nitrogen adsorption revealed higher surface areas than the outer surface calculated for compact, smooth particles from the experimentally determined diameters. This was attributed to a surface roughness and porosity of the nanoparticles. ${ }^{23}$ The nitrogen adsorption isotherms of the silica nanospheres were studied. They exhibit a type IV pattern, ${ }^{24}$ indicative of the presence of defined mesopores in the silica framework (Figure S9, Supporting Information). The BET (Brunauer-EmmettTeller) surface area was found to be much higher than calculated for compact spheres $\left(239 \mathrm{~m}^{2} \mathrm{~g}^{-1}\right.$ vs $65 \mathrm{~m}^{2} \mathrm{~g}^{-1}$ calculated for $50 \mathrm{~nm}$ particle size), and the pore size distribution is centered at mesopore diameters around $20 \mathrm{~nm}$. These mesopores correspond to interstices between packed particles. ${ }^{23 a, 25}$ However, this analysis has a lower limit of ca. $2 \mathrm{~nm}$. The isotherm profile also suggests the presence of ultramicropores $(<2 \mathrm{~nm})$, which were also previously reported by Vrij et al. for silica nanoparticles prepared by Stöber synthesis (cf. Figure S9, Supporting Information). ${ }^{26}$ The contribution of these micropores has a significant impact on the surface area obtained by the BET method. However, such small pores should be accessible to small molecules like $\mathrm{N}_{2}$, but not to the metal complexes which can not penetrate into the silica nanoparticle interior via the micropores. The finding that nonetheless fragmentation occurred during polymerization prompted a closer study of this process.

Fragmentation Process. The fragmentation of supported catalysts has been studied by various techniques such as electron microscopy (SEM, TEM), ${ }^{10,11 \mathrm{~b}} \mathrm{X}$-ray microscopy, ${ }^{27}$ confocal fluorescence microscopy ${ }^{28}$ and videomicroscopy. ${ }^{29}$ Depending on the nature of the support, different particle growth mechanisms and fragmentation behavior have been described. ${ }^{3,10}$ For silica-supported metallocene catalysts, Fink et al. reported a "layer by layer" fragmentation process. Starting from the external surface it proceeds to the center of the particle, induced by hydraulic force of the growing polymer, until the catalyst is entirely fragmented. ${ }^{3,30}$ A different particle growth mechanism has been observed with $\mathrm{MgCl}_{2}$-supported Ziegler catalysts. The fragmentation occurs at an early stage of the polymerization, producing a large number of small subparticles (multigrain model). ${ }^{31}$ Another model was also suggested for this system, in which agglomerates of primary catalyst crystallites $(10-30$ $\mathrm{nm}$ size) produce polymer subglobules within the growing particle. ${ }^{32}$ More recently, Loos et al. observed two types of fragmentation behavior for a metallocene/MAO/silica catalyst system via SEM: a layer-by-layer fragmentation and an instantaneous break-up of the support, depending on the operating conditions used (catalyst distribution on the support, monomer, and polymerization conditions). ${ }^{10 \mathrm{~d}}$

We followed the fragmentation behavior of silica nanoparticles by TEM analyses of cross-sections of single particles, formed at different polymerization times. From an ongoing ethylene polymerization with the silica nanoparticle-supported catalyst, aliquots were drawn at different polymerization times (entries 5, 5', and 5" in Table 1). From the beginning of the polymerization on, apparently fragmentation occurs (Figure 4, left). However, further fragmentation of the fragments observed after $15 \mathrm{~min}$ occurs to finally afford very small fragments of ca. 8 to $12 \mathrm{~nm}$ size, which are homogeneously dispersed in the polymer particles.

For the system studied, we suggest a fragmentation model which differs from the well-known multigrain model. Iler suggested that silica particles obtained by the Stöber method are formed by uniform aggregation of much smaller ultimate primary particles $(\sim 5 \mathrm{~nm}),{ }^{25}$ and the observation of ultramicropores $(<2 \mathrm{~nm})$ in our silica particles corroborates this suggestion. Thus, the initial fragmentation process could not be due to polymer growth in between primary particles. Such a silica nanoparticle structure could account for the observed fragmentation behavior. The dense polymer growth at the particle outer surface and the resulting force exert on the particle may cause fragmentation. Under this exerted force, fragmentation occurs until small ultimate primary particles are obtained (8 nm) (Scheme 5). 

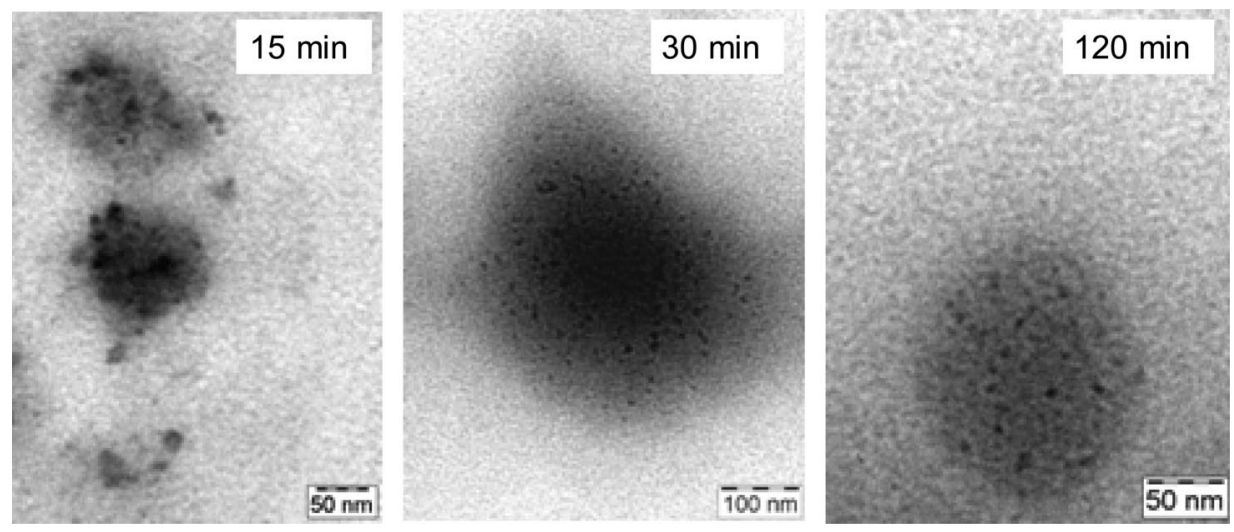

Figure 4. TEM images of the cross-section of polyethylene particles drawn from an ongoing polymerization at different times.
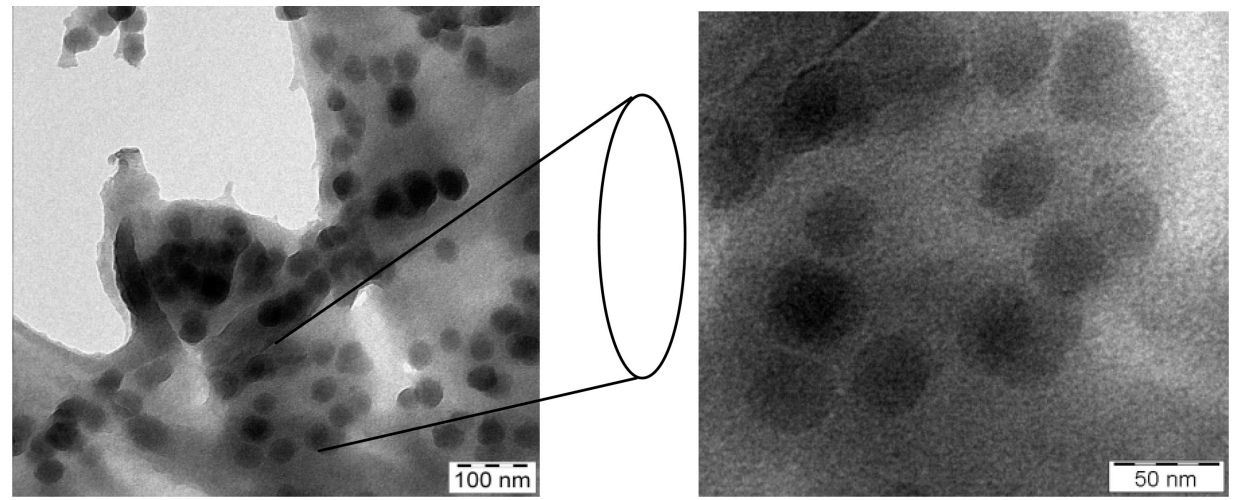

Figure 5. TEM images of cross-section of polyethylene-silica composite obtained by polymerization with nonsupported catalyst physically mixed with silica nanoparticles.

Silica nanoparticles with covalently bound catalyst, which were recovered from a polymerization experiment that failed to afford any polymer due to impurities in the solvent batch employed, were studied. TEM revealed intact nonfragmented silica nanoparticles exclusively. That is, fragmentation indeed only occurs upon polymer formation. Fragmentation by other means, e.g. a conceivable bursting of the particles by ethylene gas trapped in the micropores upon pressure release can be excluded. To further confirm that polymer formation by catalyst covalently bound to the particle surface causes the fragmentation, the material obtained from polymerization with nonsupported catalyst physically mixed with a silica nanoparticle dispersion (vide supra) was analyzed further. TEM on thin crosssections confirms the presence of the intact original silica particles exclusively; no fragmentation is observed (Figure 5).

\section{Conclusion and Summary}

$\mathrm{N}^{\wedge} \mathrm{O}$-chelated titanium complexes can be bound covalently to silica nanoparticles via condensation of a trimethoxysilaneterminated linker with residual silanol groups on the lipophilically modified particle surface. By comparison to the large number of studies on immobilization of metallocene and postmetallocene polymerization catalysts on macroscopic, if porous, silica structures, this procedure affords nonaggregated individual silica nanoparticles (ca. $50 \mathrm{~nm}$ diameter) with catalyst bound to the outer surface. This well-defined, uniform structure also enables a high level of characterization. In ethylene polymerization, the supported catalysts possess single site characteristics. Ultra high molecular weight polyethylene can be obtained. The polymer particles obtained with the nanoparticle-supported catalysts possess a uniform spherical morphology, with a particle size in the submicron regime. During this polymerization, surprisingly, a complete fragmentation of the nanoparticle support to fragments of ca. $10 \mathrm{~nm}$ size occurs. Fragmentation occurs by force exert by polymer formation on the particle outer surface by the covalently bound catalyst. This breaking up of the particles may be facilitated by micropores (not accessible to the catalyst) in the particles. Observation of particle fragmentation starting from such small, uniform entities is novel. Morphologically uniform submicron particles may contribute to resolve the notorious issue of processing of UHMWPE, which hinders more widespread application of this environmentally benign low-cost engineering plastic.

\section{Experimental Section}

Materials and General Considerations. All reactions (except Stöber synthesis and silica modification with octylsilane) with air and moisture sensitive compounds were carried out under a dry nitrogen or argon atmosphere in dryboxes and/or using standard Schlenk line techniques.Toluene, THF and DMSO were distilled from $\mathrm{Na}, \mathrm{Na}$ /benzophnone and $\mathrm{CaH}_{2}$ respectively under argon, and were degassed by repeated freeze-pump thaw cycles prior to use. Ethanol and ammonia solution $\left(25 \% \mathrm{NH}_{3}\right.$ in water) were purchased from Riedel-de Haen and used as received. Tetraethyl orthosilicate (TEOS) 98\% purchased from Aldrich was distilled prior to use. All other solvents used were analytical grade. The organosilanes trimethoxy(octyl)silane, 3-(m-aminophenoxy)-propyltrimethoxysilane, and 3-chloropropyltrimethoxysilane were purchased from Aldrich and ABCR respectively, and used as received. 3-tert-Butyl2-hydroxybenzaldehyde and $\mathrm{TiCl}_{4}$ were purchased from Aldrich and used as received. Ethylene of 3.5 grade (99.95\% purity) supplied by Gerling and Holz was used without further purification. $\mathrm{N}$-(Tetrafluoro-4-hydroxyphenyl)amine ${ }^{33}$ and $\left[\mathrm{Ti}\left({ }^{\mathrm{i}} \mathrm{OPr}\right)_{2} \mathrm{Cl}_{2}\right]^{34}$ were prepared according to literature procedures.

NMR spectra were recorded on a Varian Inova 400 instrument. ${ }^{1} \mathrm{H}$ chemical shifts were referenced to residual protiated solvent. The assignment of chemical shifts for ligands and complexes is 
based on ${ }^{1} \mathrm{H}-,{ }^{1} \mathrm{H},{ }^{1} \mathrm{H}$-gCOSY,$\left({ }^{1} \mathrm{H}\right){ }^{13} \mathrm{C}$-, DEPT135-, ${ }^{1} \mathrm{H},{ }^{13} \mathrm{C}$-gHMQC, and ${ }^{1} \mathrm{H},{ }^{13} \mathrm{C}$-gHMBC NMR experiments. Elemental analyses were performed up to $950{ }^{\circ} \mathrm{C}$ on an Elementar Vario EL. ${ }^{1} \mathrm{H},{ }^{13} \mathrm{C}$ and ${ }^{29} \mathrm{Si}$ solid-state CP/MAS NMR of silica nanoparticles were recorded at the Institute of Macromolecular Chemistry at the University of Freiburg on a Bruker Avance 500 solid-state NMR spectrometer operating at $500 \mathrm{MHz}$ for ${ }^{1} \mathrm{H}, 125.775 \mathrm{MHz}$ for ${ }^{13} \mathrm{C}$ and 99.375 $\mathrm{MHz}$ for ${ }^{29} \mathrm{Si}$. The samples were spun at the magic angle at $8 \mathrm{kHz}$ using $4 \mathrm{~mm}$ rotors. Cross-polarization was employed with a contact time and a relaxation delay of $3 \mathrm{~ms}$ and $3 \mathrm{~s}$. Dynamic light scattering (DLS) on diluted silica nanoparticles dispersion was performed on a Malvern Nano-ZS ZEN 3600 particle sizer (173 ${ }^{\circ}$ backscattering). The autocorrelation function was analyzed using the Malvern dispersion technology software 3.30 algorithm to obtain volume weighted particle size distributions. Differential scanning calorimetry (DSC) was performed on a Netzsch DSC 204 F1 at a heating rate of $10 \mathrm{~K} \mathrm{~min}^{-1}$. The polymers were investigated in the temperature range of -100 to $+160{ }^{\circ} \mathrm{C}$. DSC data reported are second heats. Gel permeation chromatography (GPC) was carried out in 1,2,4-trichlorobenzene with $0.0125 \%$ BHT stabilizer at 160 ${ }^{\circ} \mathrm{C}$ at a flow rate of $1 \mathrm{~mL} \mathrm{~min}{ }^{-1}$ on a Polymer Laboratories 220 instrument equipped with Olexis columns with differential refractive index, viscosity and light scattering $\left(15^{\circ}\right.$ and $\left.90^{\circ}\right)$ detectors. Data reported were determined via triple detection. The instrument was calibrated with narrow polystyrene and polyethylene standards. Data given is referenced to linear polyethylene. Transmission Electron Microscopy (TEM) was carried out on a Zeiss Libra 120 apparatus using an acceleration voltage of $120 \mathrm{kV}$. Silica nanoparticle samples were prepared by applying a drop of the dispersion to a carboncoated grid. Polyethylene samples were embedded in Epofix, and $70 \mathrm{~nm}$ sections were cut with a Leica microtome at room temperature. Highly resolved element distribution images were acquired by element specific imaging (ESI), operating at the energy loss of titanium and chloride, respectively. Scanning electron microscopy (SEM) was carried out on a Zeiss cross beam 1540 XB instrument. IR spectra were carried out on a Perkin-Elmer IR FT 2000.

Adsorption measurements were performed at $-196{ }^{\circ} \mathrm{C}$ using a Micrometrics Tristar volumetric adsorption analyzer. Before the measurements, the samples were degassed at $150{ }^{\circ} \mathrm{C}$ for $12 \mathrm{~h}$ under vacuum, until a residual pressure of $10^{-6}$ mbar was reached. The total pore volume was estimated from the volume of $\mathrm{N}_{2}$ adsorbed at a relative pressure of $P / P_{0}=0.99$.

Preparation and Modification of Silica Particles. The silica particles were prepared according to the Stöber method. ${ }^{14}$ First, $400 \mathrm{~mL}$ of ethanol and $21 \mathrm{~mL}$ of an ammonia solution $\left(25 \% \mathrm{NH}_{3}\right.$ in water) were mixed in a $1 \mathrm{~L}$ flask. After stirring vigorously for $5 \mathrm{~min}$, and gently for another $30 \mathrm{~min}, 16 \mathrm{~mL}$ of TEOS were added and stirred again for $12 \mathrm{~h}$ at room temperature. The silica dispersions obtained have an average particle size of $50 \mathrm{~nm}$ determined by DLS. Modification of the silica surface was achieved by adding an excess of trimethoxy(octyl)silane ( 16 to $24 \mu \mathrm{mol} \mathrm{m}^{-2}$; ca. $2-3$ times the silanol surface concentration, estimated to be $\left.8 \mu \mathrm{mol} \mathrm{m}^{-2}\right)^{15}$ to the silica dispersion (directly after synthesis). The mixture was stirred for $24 \mathrm{~h}$, during which the stability of the dispersion was monitored by DLS. $200 \mathrm{~mL}$ of toluene were added to the dispersion of modified silica, and the mixture was purified by azeotropic distillation at ambient pressure until complete removal of the ammonia and ethanol. The dispersion was further purified of excess organosilane and residual impurities by a series of centrifugation $(2 \mathrm{~h}$ at $6500 \mathrm{rpm})$ and redispersion (in dry toluene) cycles. The average particle size and particle size distribution were monitored by DLS after each centrifugation and redisperison steps. The modified silica particles were stored as a dispersion in dry and degassed toluene, or dried for $12 \mathrm{~h}$ at $50{ }^{\circ} \mathrm{C}$ under vacuum to afford a dry powder which was stored in the glovebox.

Synthesis of $N$-(3-tert-Butylsalicylidene)-3-(trimethoxysilyl)propoxyaniline (1). To a toluene solution of 3-( $m$-aminophenoxy)propyltrimethoxysilane $(0.93 \mathrm{~mL}, 3.7 \mathrm{mmol})$ and $5 \mathrm{mg}$ of $p$-toluenesulfonic acid hydrate in a $50 \mathrm{~mL}$ flask was added dropwise 2-tert-butylsalicylaldehyde $(0.64 \mathrm{~mL}, 3.7 \mathrm{mmol})$ under nitrogen.
The mixture was heated to reflux for $24 \mathrm{~h}$. The solvent was evaporated, and the yellow oil obtained was washed with cold pentane and dried under vacuum $\left(10^{-3} \mathrm{mbar}\right)$ to yield analytically pure 1 as an oil in quantitative yield (1. $47 \mathrm{~g}) .{ }^{1} \mathrm{H}$ NMR (399.8 $\left.\mathrm{MHz}, \mathrm{C}_{6} \mathrm{D}_{6}, 25^{\circ} \mathrm{C}\right): \delta 13.88(\mathrm{~s}, 1 \mathrm{H}, \mathrm{OH}), 8.62(\mathrm{~s}, 1 \mathrm{H}, \mathrm{CH}=\mathrm{N})$, $7.41\left(\mathrm{~d}, J_{\mathrm{H}-\mathrm{H}}=1.3 \mathrm{~Hz} 1 \mathrm{H}, \mathrm{Ar}-H\right), 7.28(\mathrm{~m}, 2 \mathrm{H}, \mathrm{Ar}-H), 6.86(\mathrm{~m}$, $4 \mathrm{H}, \mathrm{Ar}-\mathrm{H}), 3.92\left(\mathrm{t}, 2 \mathrm{H}, J_{\mathrm{H}-\mathrm{H}}=6.5 \mathrm{~Hz},-\mathrm{OCH}_{2} \mathrm{CH}_{2} \mathrm{C}-\right), 3.60(\mathrm{~s}$, $\left.9 \mathrm{H},-\mathrm{SiOCH}_{3}\right), 1.93\left(\mathrm{~m}, 2 \mathrm{H},-\mathrm{OCH}_{2} \mathrm{CH}_{2} \mathrm{CH}_{2}-\right), 1.48$ (s, $9 \mathrm{H}$, $t$-Bu), 0.83 (t, $\left.2 \mathrm{H}, J_{\mathrm{H}-\mathrm{H}}=8.05 \mathrm{~Hz},-\mathrm{CH}_{2} \mathrm{CH}_{2} \mathrm{CH}_{2} \mathrm{Si}-\right) .{ }^{13} \mathrm{C}\left({ }^{1} \mathrm{H}\right)$ NMR (100.5 MHz, $\left.\mathrm{C}_{6} \mathrm{D}_{6}, 25{ }^{\circ} \mathrm{C}\right): \delta 163.7(\mathrm{CH}=\mathrm{N}), 161.2\left(\mathrm{C}_{\mathrm{q}}\right.$, $\left.\mathrm{ArC}-\mathrm{OCH}_{2}-\right), 160.5(\mathrm{ArC}-\mathrm{OH}), 150.2\left(\mathrm{C}_{\mathrm{q}}, \mathrm{ArC}-\mathrm{N}\right), 137.9\left(\mathrm{C}_{\mathrm{q}}\right.$, $\mathrm{ArC}-t-\mathrm{Bu}), 131.1,130.7,130.22$ (CHAr), $119.6\left(\mathrm{C}_{\mathrm{q}}, \operatorname{ArC}-\mathrm{CN}\right)$, 118.6 (CHAr), 113.5, 113.4 (CHAr), 108.1 (CHAr), 69.9 $\left(-\mathrm{OCH}_{2} \mathrm{CH}_{2} \mathrm{C}-\right), 50.3\left(-\mathrm{SiOCH}_{3}\right), 35.2\left(-\mathrm{C}\left(\mathrm{CH}_{3}\right)_{3}, t-\mathrm{Bu}\right), 29.6$ $\left(-\mathrm{C}\left(\mathrm{CH}_{3}\right)_{3}, t-\mathrm{Bu}\right), 23.1 \quad\left(-\mathrm{OCH}_{2} \mathrm{CH}_{2} \mathrm{CH}_{2}-\right), 5.9\left(-\mathrm{CH}_{2} \mathrm{CH}_{2}-\right.$ $\left.\mathrm{CH}_{2} \mathrm{Si}-\right)$. Anal. Calcd for $\mathrm{C}_{23} \mathrm{H}_{33} \mathrm{NO}_{5} \mathrm{Si}\left(431.6 \mathrm{~g} \mathrm{~mol}^{-1}\right)$ : C, 64.01; H, 7.71; N, 3.25. Found: C: 63.81; H: 7.64; N: 3.19.

Synthesis of 4-(Trimethoxysilyl)propoxy-2,3,5,6-tetrafluoroaniline (A). To a suspension of $\mathrm{NaH}$ in toluene $(0.13 \mathrm{~g}, 5.3 \mathrm{mmol})$ was added a solution of $N$-(tetrafluoro-4-hydroxyphenyl)amine $(0.88$ $\mathrm{g}, 4.8 \mathrm{mmol})$ in toluene/DMSO $(10 / 6 \mathrm{~mL})$ via cannula under nitrogen. The mixture was refluxed for $24 \mathrm{~h}$, then the temperature was decreased to $70{ }^{\circ} \mathrm{C}$, and 3-chloropropyltrimethoxysilane $(0.9$ $\mathrm{mL}, 4.8 \mathrm{mmol}$ ) was added dropwise with a syringe under nitrogen. The mixture was heated to reflux for another $12 \mathrm{~h}$. After cooling to room temperature, the mixture was filtered, and the filtrate was evaporated at reduced pressure. The crude oil obtained was purified by Kugelrohr distillation to give $\mathbf{A}$ as dark-blue oil in $68 \%$ yield. ${ }^{1} \mathrm{H}$ NMR (399.8 MHz, $\left.\mathrm{CDCl}_{3}, 25^{\circ} \mathrm{C}\right): \delta 4.01\left(\mathrm{t}, 2 \mathrm{H}, J_{\mathrm{H}-\mathrm{H}}=6.4\right.$ $\mathrm{Hz},-\mathrm{OCH}_{2} \mathrm{CH}_{2} \mathrm{CH}_{2}-$ ), 3.75 (bs, $2 \mathrm{H},-\mathrm{NH}_{2}$ ), 3.56 (bs, $6 \mathrm{H}$, $-\mathrm{SiOMe}$ ), $1.83\left(\mathrm{~m}, 2 \mathrm{H},-\mathrm{OCH}_{2} \mathrm{CH}_{2} \mathrm{CH}_{2}-\right), 0.77$ (bt, $2 \mathrm{H}, J_{\mathrm{H}-\mathrm{H}}$ $\left.=6.1 \mathrm{~Hz},-\mathrm{OCH}_{2} \mathrm{CH}_{2} \mathrm{CH}_{2}-\right) .{ }^{13} \mathrm{C}\left({ }^{1} \mathrm{H}\right) \mathrm{NMR}\left(100.5 \mathrm{MHz}, \mathrm{C}_{6} \mathrm{D}_{6}\right.$, $\left.25^{\circ} \mathrm{C}\right): \delta$ 143.8, 141.3, $\left(\mathrm{C}_{\mathrm{q}}, \mathrm{ArC}-\mathrm{F}\right), 136.1\left(\mathrm{C}_{\mathrm{q}}, \mathrm{ArC}-\mathrm{O}-\right), 121.94$ $\left(\mathrm{C}_{\mathrm{q}}, \mathrm{ArC}-\mathrm{NH}_{2}\right), 77.7\left(-\mathrm{OCH}_{2} \mathrm{CH}_{2} \mathrm{C}-\right), 50.1\left(-\mathrm{SiOCH}_{3}\right), 23.7$ ( $-\mathrm{OCH}_{2} \mathrm{CH}_{2} \mathrm{CH}_{2}-$ ), $5.4\left(-\mathrm{CH}_{2} \mathrm{CH}_{2} \mathrm{CH}_{2} \mathrm{Si}-\right.$ ).

Synthesis of $N$-(3-tert-butylsalicylidene)-3-(trimethoxysilyl)propoxy-2,3,5,6-tetrafluoroaniline (2). To a toluene solution of A $(320 \mathrm{mg}, 1.51 \mathrm{mmol})$ and $5 \mathrm{mg}$ of $p$-toluene sulfonic acid hydrate in a $50 \mathrm{~mL}$ flask was added dropwise 2-tert-butylsalicylaldehyde $(0.25 \mathrm{~mL}, 1.51 \mathrm{mmol})$ under nitrogen flow. The mixture was heated to reflux for $24 \mathrm{~h}$. During refluxing, a small amount of precipitate was observed $(5-10 \%)$, probably due to hydrolysis and polycondensation processes of part of the siloxane moieties by the water formed by the condensation reaction of aldehyde with aniline. The solvent was evaporated, and the dark-yellow oil obtained was dissolved in $\mathrm{CH}_{2} \mathrm{Cl}_{2}$ and precipitated with cold pentane. The precipitate was isolated and dried under vacuum $\left(10^{-3} \mathrm{mbar}\right)$ to yield 3 as dark-yellow oil in 64\% yield (493 mg). ${ }^{1} \mathrm{H}$ NMR (399.8 $\mathrm{MHz}, \mathrm{CDCl}_{3}, 25{ }^{\circ} \mathrm{C}$ ): $\delta 13.47$ (bs, $1 \mathrm{H},-\mathrm{OH}$ ), 8.29 (bs, $1 \mathrm{H}$, $-\mathrm{CH}=\mathrm{N}-$ ), 7.31 (bs, $1 \mathrm{H} \mathrm{ArH}$ ), 6.81 (bs, $1 \mathrm{H} \mathrm{ArH}$ ), 6.69 (bs, $1 \mathrm{H}$ $\mathrm{ArH}$ ), 4.05 (bs, $2 \mathrm{H},-\mathrm{OCH}_{2} \mathrm{CH}_{2} \mathrm{CH}_{2}-$ ), 3.02 (bs, 6H, - $\mathrm{SiOMe}$ ), $1.96\left(\mathrm{~m}, 2 \mathrm{H},-\mathrm{OCH}_{2} \mathrm{CH}_{2} \mathrm{CH}_{2}-\right), 1.52(\mathrm{~s}, 9 \mathrm{H}, t-\mathrm{Bu}), 0.93(\mathrm{bs}, 2 \mathrm{H}$, $\left.-\mathrm{OCH}_{2} \mathrm{CH}_{2} \mathrm{CH}_{2}-\right) .{ }^{13} \mathrm{C}\left({ }^{1} \mathrm{H}\right) \mathrm{NMR}\left(100.5 \mathrm{MHz}, \mathrm{C} 6 \mathrm{D} 6,25{ }^{\circ} \mathrm{C}\right): \delta$ $170.3(-\mathrm{CH}=\mathrm{N}-), 161.5\left(\mathrm{C}_{\mathrm{q}}, \mathrm{ArC}-\mathrm{OH}\right), 143.2,140.8\left(\mathrm{C}_{\mathrm{q}}\right.$, $\operatorname{ArC}-\mathrm{F}), 138.36\left(\mathrm{C}_{\mathrm{q}}, \operatorname{ArC}-t-\mathrm{Bu}\right), 135.5\left(\mathrm{C}_{\mathrm{q}}, \operatorname{ArC}-\mathrm{O}-\right), 132.0$, 131.8 (CHAr), $122.1\left(\mathrm{C}_{\mathrm{q}}, \operatorname{ArC}-\mathrm{N}\right), 118.9\left(\mathrm{C}_{\mathrm{q}}, \operatorname{ArC}-\mathrm{CN}\right), 77.4$ $\left(-\mathrm{OCH}_{2} \mathrm{CH}_{2} \mathrm{C}-\right), 50.2\left(-\mathrm{SiOCH}_{3}\right), 35.1\left(-\mathrm{C}\left(\mathrm{CH}_{3}\right)_{3}, t-\mathrm{Bu}\right), 29.5$ $\left(-\mathrm{C}\left(\mathrm{CH}_{3}\right)_{3}, t-\mathrm{Bu}\right), 24.1 \quad\left(-\mathrm{OCH}_{2} \mathrm{CH}_{2} \mathrm{CH}_{2}-\right), 7.8\left(-\mathrm{CH}_{2} \mathrm{CH}_{2}-\right.$ $\left.\mathrm{CH}_{2} \mathrm{Si}-\right)$.

Synthesis of Dichlorobis[ $\kappa^{2}-N, O-6-(3-($ trimethoxysilyl)propoxyphenylimino)-2-tert-butylphenolato]titanium(IV) (3). To a stirred solution of $\left[\mathrm{TiCl}_{2}\left(\mathrm{O}^{\mathrm{i} P r}\right)_{2}\right](0.058 \mathrm{~g}, 0.245 \mathrm{mmol})$ in THF (5 $\mathrm{mL})$ was added a solution of $\mathbf{1}(0.210 \mathrm{~g}, 0.49 \mathrm{mmol})$ in THF (5 $\mathrm{mL}$ ) dropwise at $0{ }^{\circ} \mathrm{C}$. The mixture was allowed to warm to room temperature and stirred for $16 \mathrm{~h}$. After removal of the solvent, the product was extracted with $\mathrm{CH}_{2} \mathrm{Cl}_{2}$ and precipitated in cold pentane. Filtration of the product followed by drying under vacuum $\left(10^{-3}\right.$ mbar) gave an orange solid in $74 \%$ yield $(0.173 \mathrm{~g}) .{ }^{1} \mathrm{H}$ NMR $(399.8$ $\left.\mathrm{MHz}, \mathrm{THF}-d_{8}, 25^{\circ} \mathrm{C}\right): \delta 8.39(\mathrm{~s}, 2 \mathrm{H}, \mathrm{CH}=\mathrm{N}), 7.71\left(\mathrm{~d}, J_{\mathrm{H}-\mathrm{H}}=\right.$ $1.5 \mathrm{~Hz}, 2 \mathrm{H}, \mathrm{Ar}-\mathrm{H}), 7.12-7.47$ (bm, 8H, $\mathrm{Ar}-H), 6.80(\mathrm{~m}, 4 \mathrm{H}$, $\mathrm{Ar}-\mathrm{H}$ ), 4.14 (bt, $4 \mathrm{H}, J_{\mathrm{H}-\mathrm{H}}=6.6 \mathrm{~Hz},-\mathrm{OCH}_{2} \mathrm{CH}_{2} \mathrm{C}-$ ), 3.78 (bs, 
$18 \mathrm{H},-\mathrm{SiOCH}_{3}$ ), 2.11 (bs, $4 \mathrm{H},-\mathrm{OCH}_{2} \mathrm{CH}_{2} \mathrm{CH}_{2}-$ ), 1.69 (s, $18 \mathrm{H}$, $t$-Bu $), 0.98\left(\mathrm{~m}, 4 \mathrm{H}, J_{\mathrm{H}-\mathrm{H}}=8.05 \mathrm{~Hz},-\mathrm{CH}_{2} \mathrm{CH}_{2} \mathrm{CH}_{2} \mathrm{Si}-\right) \cdot{ }^{13} \mathrm{C}\left({ }^{1} \mathrm{H}\right)$ NMR (100.5 MHz, THF- $\left.d_{8}, 25^{\circ} \mathrm{C}\right): \delta 167.3(\mathrm{CH}=\mathrm{N}), 161.2,159.2$ and $153.7\left(\mathrm{C}_{\mathrm{q}}, A r\right), 138.8\left(\mathrm{C}_{\mathrm{q}}, \operatorname{ArC}-\mathrm{N}\right), 134.4,133.2,129.4(\mathrm{CHAr})$, $125.2\left(\mathrm{C}_{9}, A r\right), 121.3,115.4,113.0$ and 110.0 (CHAr), 70.1 $\left(-\mathrm{OCH}_{2} \mathrm{CH}_{2} \mathrm{C}-\right), 50.5\left(-\mathrm{SiOCH}_{3}\right), 35.5\left(-\mathrm{C}\left(\mathrm{CH}_{3}\right)_{3}, t-\mathrm{Bu}\right), 29.5$ $\left(-\mathrm{C}\left(\mathrm{CH}_{3}\right)_{3}, t-\mathrm{Bu}\right), 22.7\left(-\mathrm{OCH}_{2} \mathrm{CH}_{2} \mathrm{CH}_{2}-\right), 5.45\left(-\mathrm{CH}_{2} \mathrm{CH}_{2}-\right.$ $\left.\mathrm{CH}_{2} \mathrm{Si}-\right)$. Anal. Calcd for $\mathrm{C}_{46} \mathrm{H}_{64} \mathrm{Cl}_{2} \mathrm{~N}_{2} \mathrm{O}_{10} \mathrm{Si}{ }_{2} \mathrm{Ti}\left(979.95 \mathrm{~g} \mathrm{~mol}^{-1}\right)$ : C, 56.38; H, 6.58; N, 2.86. Found: C:56.25; H: 6.49; N:2.85.

Synthesis of Dichlorobis $\left[K^{2}-N, O-6-(4-(\right.$ trimethoxysilyl)propoxy-2,3,5,6-tetrafluorophenylimino)-2-tert-butylphenolato]titanium(IV) (4). To a stirred solution of $\left[\mathrm{TiCl}_{2}\left(\mathrm{O}^{\mathrm{P} P r}\right)_{2}\right](0.023 \mathrm{~g}, 0.097$ $\mathrm{mmol})$ in THF (3 mL) was added a solution of $2(0.098 \mathrm{~g}, 0.194$ $\mathrm{mmol})$ in THF $(2 \mathrm{~mL})$ dropwise at $0{ }^{\circ} \mathrm{C}$. The mixture was allowed to warm to room temperature, and stirred for $16 \mathrm{~h}$. After removal of the solvent, the product was extracted with $\mathrm{CH}_{2} \mathrm{Cl}_{2}$ and precipitated in cold pentane. Filtration of the product followed by drying under vacuum $\left(10^{-3} \mathrm{mbar}\right)$ afforded a light-brown powder in $48 \%$ yield $(0.052 \mathrm{~g}) .{ }^{1} \mathrm{H}$ NMR $\left(399.8 \mathrm{MHz}\right.$, THF- $\left.d_{8}, 25^{\circ} \mathrm{C}\right): \delta$ $8.86(\mathrm{~s}, 2 \mathrm{H}, \mathrm{CH}=\mathrm{N}), 7.87\left(\mathrm{~d}, J_{\mathrm{H}-\mathrm{H}}=7.1 \mathrm{~Hz}, 2 \mathrm{H}, \mathrm{Ar}-H\right), 7.66(\mathrm{~d}$, $\left.J_{\mathrm{H}-\mathrm{H}}=2.5 \mathrm{~Hz} 2 \mathrm{H}, \mathrm{Ar}-H\right), 7.15\left(\mathrm{t}, J_{\mathrm{H}-\mathrm{H}}=7.5 \mathrm{~Hz}, 2 \mathrm{H}, \mathrm{Ar}-H\right)$, 4.47 (bs, $4 \mathrm{H},-\mathrm{OCH}_{2} \mathrm{CH}_{2} \mathrm{C}-$ ), 3.75 (bs, $18 \mathrm{H},-\mathrm{SiOCH}_{3}$ ), 2.17 (bs, $4 \mathrm{H},-\mathrm{OCH}_{2} \mathrm{CH}_{2} \mathrm{CH}_{2}-$ ), $1.70(\mathrm{~s}, 18 \mathrm{H}, t-\mathrm{Bu}), 1.11$ (bs, $4 \mathrm{H}$, $\left.-\mathrm{CH}_{2} \mathrm{CH}_{2} \mathrm{CH}_{2} \mathrm{Si}-\right) .{ }^{13} \mathrm{C}\left({ }^{1} \mathrm{H}\right) \mathrm{NMR}\left(100.5 \mathrm{MHz}, \mathrm{THF}-d_{8}, 25^{\circ} \mathrm{C}\right): \delta$ $173.3(C H=\mathrm{N}), 164.1\left(\mathrm{C}_{\mathrm{q}}, \operatorname{ArC}-\mathrm{O}\right), 143.1\left(\mathrm{C}_{\mathrm{q}}, \operatorname{ArC}-\mathrm{N}\right), 140.6$ (CHAr), $138.8\left(\mathrm{C}_{\mathrm{q}}, \mathrm{ArC}-\mathrm{F}\right), 136.3\left(\mathrm{C}_{\mathrm{q}}, \mathrm{ArC}-\mathrm{O}-\right)$, 135.2 (CHAr), $133.9\left(\mathrm{C}_{\mathrm{q}}, \quad \operatorname{ArC}-\mathrm{F}\right), 122.1\left(\mathrm{C}_{\mathrm{q}}, \quad A r\right), 119.9\left(\mathrm{C}_{\mathrm{q}}, \quad\right.$ Ar $), 77.6$ $\left(-\mathrm{OCH}_{2} \mathrm{CH}_{2} \mathrm{C}-\right), 50.2\left(-\mathrm{SiOCH}_{3}\right), 35.2\left(-C\left(\mathrm{CH}_{3}\right)_{3}, t-\mathrm{Bu}\right), 29.7$ $\left(-\mathrm{C}\left(\mathrm{CH}_{3}\right)_{3}, t-\mathrm{Bu}\right), 25.7\left(-\mathrm{OCH}_{2} \mathrm{CH}_{2} \mathrm{CH}_{2}-\right), 6.7\left(-\mathrm{CH}_{2} \mathrm{CH}_{2}\right.$ $\left.\mathrm{CH}_{2} \mathrm{Si}-\right)$.

Binding of Metal Complexes to Silica Nanoparticles. To the lipophilically modified silica nanoparticle dispersion (obtained after sonication of the mixture) in toluene ( $55 \mathrm{~nm}$ size, $282 \mathrm{mg}$ of silica in $40 \mathrm{~mL}$ ) was added dropwise a solution of complex $\mathbf{3}$ or $\mathbf{4}$, respectively, $(30 \mu \mathrm{mol})$ in toluene $(3 \mathrm{~mL})$ in the glovebox. The clear yellow solution was then gently stirred for $24 \mathrm{~h}$. After $24 \mathrm{~h}$, an aliquot was taken off from the stable dispersion for DLS analyses. The dispersion was transferred in the glovebox to a tight screw-cap vial, and the dispersion was purified from excess of catalyst by a series of centrifugations $(2 \mathrm{~h}, 6500 \mathrm{rpm})$ and redispersions in toluene (until the supernatant was completely colorless). Drying of the silica dispersions for $24 \mathrm{~h}$ at $50{ }^{\circ} \mathrm{C}$ under vacuum afforded a yellow powder which was stored in the glovebox.

Characterization of the Silica Nanoparticles. Silica nanoparticles were characterized after octylsilane modification, and after the grafting of the metal complexes. Elemental analysis (wt \% C) was carried out on dried silica samples before and after octylsilane modification. The carbon content in the samples before octylsilane modification is due to unhydrolyzed ethoxy groups $\left(\mathrm{OC}_{2} \mathrm{H}_{5}\right)$ trapped in the particles as terminal functions, and the hydrogen content originates both from water and $\mathrm{OC}_{2} \mathrm{H}_{5}$ groups. After modification, a significant increase of the carbon content was observed, indicative of the presence of organosilane on the silica surface (cf. Table S1, Supporting Information). From carbon content analyses, the amount of octyl-grafted silica was estimated according to the Berendsen equation. ${ }^{35}$ It was found to be between 16 and $22 \mu \mathrm{mol}$ of silane per $\mathrm{m}^{2}$ of silica (corresponding to $9-13$ silane molecules per $\mathrm{nm}^{2}$ ). ${ }^{17}$ Further evidence of grafting of organosilane were also obtained by solid state CP/MAS NMR and IR spectroscopy (Supporting Information, Figures S1, S2, and S3).

Elemental analysis (wt \% C) was also carried out on dried octylsilane-modified silica samples after grafting of the catalyst, in which the presence of nitrogen is detected (Supporting InformationTable S1). Supported-catalyst 5 was also analyzed by solidstate CP/MAS NMR and IR (Supporting Information, Figures S1, S2, and S3). In spite of the large excess of grafted octyl-silane compared to the catalyst, some characteristic signals from the catalyst could be observed. DLS (Supporting Information, Figure S4) and TEM (Supporting Information, Figure S5) analyses were carried out on silica samples dispersed in toluene.
General Procedure for the Polymerization of Ethylene in Toluene. Polymerization reactions were conducted in a mechanically stirred $500 \mathrm{~mL}$ Büchi reactor equipped with a heating/cooling jacket supplied by a thermostat controlled by a thermocouple dipping into the polymerization mixture at a constant ethylene pressure of $2 \mathrm{~atm}$. Ethylene consumption was monitored by Bronkhorst mass-flow meters. The reactor was evacuated three times and backfilled with argon. $200 \mathrm{~mL}$ of distilled toluene further purified over columns of alumina and copper catalyst (R3-11) were directly transferred to the reactor, which was preheated to $50{ }^{\circ} \mathrm{C}$. Under stirring (600 rpm), the reactor was pressurized with 2 bar of ethylene. After $15 \mathrm{~min}$, polymerization was initiated by adding a toluene solution of the cocatalyst and after another 5 min a toluene dispersion of the nanoparticle-supported catalyst into the reactor. After the desired polymerization time, ethanol $(10 \mathrm{~mL})$ was added to terminate the polymerization, and the ethylene gas feed was terminated. To the resulting mixture were added methanol $(1 \mathrm{~L})$ and concentrated $\mathrm{HCl}(2 \mathrm{~mL})$. The polymer was collected by filtration, washed with methanol $(200 \mathrm{~mL})$, and dried in vacuum at $50{ }^{\circ} \mathrm{C}$ overnight.

Acknowledgment. Financial support by the BMBF (project 03X0007A) is gratefully acknowledged. We thank Justyna Trzaskowski for the preparation of lipophilically modified silica nanoparticles, Matthias Hagner for SEM, and Lars Bolk for GPC analyses. BET measurements and discussion thereof with Sebastian Polarz and Andreas Kuschel is acknowledged. Solid State NMR spectroscopy by Anke Hoffmann (University of Freiburg) is gratefully acknowledged. Cooperation with Ticona $\mathrm{GmbH}$ is acknowledged. S.M. is indebted to the Fonds der Chemischen Industrie and to the Hermann-Schnell Foundation.

Supporting Information Available: Elemental analyses and figures showing the FT-IR spectra, solid-state ${ }^{13} \mathrm{C}$ and ${ }^{29} \mathrm{Si} \mathrm{NMR}$, DLS traces, TEM image, and electron energy loss spectrum of nanoparticle-supported catalysts, TEM image and electron energy loss spectra of silica particles resulting from comparative experiment carried out with a salicylaldiminato-substituted titanium(IV) analogue of complex $\mathbf{4}$, but lacking the siloxane linker, examples of SEM images of polyethylenes particles, nitrogen adsorption isotherm, and derived pore size distributions of the silica nanoparticles. This material is available free of charge via the Internet at http:// pubs.acs.org.

\section{References and Notes}

(1) (a) Brintzinger, H. H.; Fischer, D.; Mülhaupt, R.; Rieger, B.; Waymouth, R. M. Angew. Chem., Int. Ed. 1995, 34, 1143. (b) Britovsek, G. J. P.; Gibson, V.; Wass, D. F. Angew. Chem., Int. Ed. 1999, 38, 428. (c) Ittel, S. D.; Johnson, L. K.; Brookhart, M. Chem. Rev. 2000, 100, 1169. (d) Mecking, S. Angew. Chem Int. Ed. 2001, 40, 534. (e) Coates, G. W.; Hustad, P. D.; Reinartz, S. Angew. Chem., Int. Ed. 2002, 41, 2236. (f) Makio, H.; Kashiwa, N.; Fujita, T. Adv. Synth. Catal. 2002, 344, 477. (g) Gibson, V. C.; Spitzmesser, S. K. Chem. Rev. 2003, 103, 283. (h) Domski, G. J.; Rose, J. M.; Coates, G. W.; Bolig, A. D.; Brookhart, M. Prog. Polym. Sci. 2007, 32, 30. (i) Berkefeld, A.; Mecking, S. Angew. Chem., Int. Ed. 2008, 47, 2538.

(2) For recent reviews, see: (a) Hlatky, G. G. Chem. Rev 2000, 100, 1347. (b) Severn, J. R.; Chadwick, J. C.; Duchateau, R.; Friederichs, N. Chem. Rev. 2005, 105, 4073.

(3) Fink, G.; Steinmetz, B.; Zechlin, J.; Pryzbyla, C.; Tesche, B. Chem. Rev. 2000, 100, 1377.

(4) Duchateau, R. Chem. Rev. 2002, 102, 3525.

(5) For selected examples of cocatalyst immobilization on silica, see: (a) Bonini, F.; Fraaije, V.; Fink, G. J. Polym. Sci., Part A: Polym. Chem. 1995, 33, 2393. (b) Welborn, H. C. U.S. Patent 4,808,561, 1989. (c) Takahashi, T. U.S. Patent 5,026,797, 1991. (d) Prades, F.; Boisson, C.; Spitz, R.; Razavi, A. Int. Patent WO 2005075525 A3, 2005.

(6) For selected examples of catalyst "covalently" anchored to silica, see: (a) Galan-Fereres, M.; Koch, T.; Hey-Hawkins, E.; Eisen, M. S. J. Organomet. Chem. 1999, 580, 145. (b) Juvaste, H.; Iiskola, E. I.; Pakkanen, T. T. J. Organomet. Chem. 1999, 587, 38. (c) Juvaste, H.; Pakkanen, T. T.; Iiskola, E. I. Organometallics 2000, 19, 4834. (d) Juvaste, H.; Pakkanen, T. T.; Iiskola, E. I. Organometallics 2000, 19, 
1729. (e) Juvaste, H.; Iiskola, E. I.; Pakkanen, T. T. J. Mol. Catal. A 1999, 150, 1. (f) Kim, I.; Han, B. H.; Ha, C.-S.; Kim, J.-K.; Suh, H. Macromolecules 2003, 36, 6689. (g) Lee, D-H.; Yoon, K.-B.; Noh, S.-K. Macromol. Rapid Commun. 1997, 18, 427. (h) Suzuki, N.; Asami, T.; Nakamura, T.; Huhn, T.; Atsushi, F.; Ichikawa, M.; Saburi, M.; Wakatsuki, Y. Chem. Lett. 1999, 341. (i) Dever, C.; Deffieux, A.; Cramail, H.; Mastroianni, S. Macromol. Rapid Commun. 2003, $24,883$.

(7) (a) Duchateau, R.; Dijkstra, T. W.; Van Santen, R. A.; Yap, G. P. A. Chem. Eur. J. 2004, 10, 3979. (b) Severn, J. R.; Duchateau, R.; Van Santen, R. A.; Ellis, D. D.; Spek, A. L. Organometallics 2002, 21, 4.

(8) For examples of well-defined supported catalysts see: (a) Nicholas, C. P.; Ahn, H.; Marks, T. J. J. Am. Chem. Soc. 2003, 125, 4325. (b) Coperet, C.; Chabanas, M.; Saint-Arroman, R. P.; Basset, J.-M. Angew. Chem., Int. Ed. 2003, 42, 156. (c) Buchmeiser, M. New J. Chem. 2004, 28, 549. (d) Buchmeiser, M. Cat. Today 2005, 105, 612. (e) Sandee, A. J.; Reek, J. N. H.; Kamer, P. C. J.; Van Leeuwen, P. W. N. M. J. Am. Chem. Soc. 2001, 123, 8468. (f) Van Leeuwen, P. W. N. M.; Sandee, A. J.; Reek, J. N. H.; Kamer, P. C. J. J. Mol. Catal. 2002, $182-183,107$

(9) For examples of immobilization of polymerization catalysts on patterned silica surface, see: (a) McKittrick, M. W.; Jones, C. W. J. Am. Chem. Soc. 2004, 126, 3052. (b) Yu, K.; McKittrick, M. W.; Jones, C. W. Organometallics 2004, 23, 4089.

(10) (a) Ferrero, M. A.; Chiovetta, M. G. Polym. Eng. Sci. 1987, 27, 1448 (b) Ferrero, M. A.; Chiovetta, M. G. Polym. Eng. Sci. 1987, 27, 1436 (c) Niegisch, W. D.; Crisafulli, S. T.; Nagel, T. S.; Wagner, B. E. Macromolecules 1992, 25, 3910. (d) Zheng, X.; Smit, M.; Chadwick, J. C.; Loos, J. Macromolecules 2005, 38, 4673.

(11) (a) Abboud, M.; Denifl, P.; Reichert, K.-H. Macromol. Mater. Eng. 2005, 290, 558. (b) Fink, G.; Tesche, B.; Korber, F.; Knoke, S Macromol. Symp. 2001, 173, 77.

(12) (a) Von Werne, T.; Patten, T. E. J. Am. Chem. Soc. 1999, 121, 7409 (b) Von Werne, T.; Patten, T. E. J. Am. Chem. Soc. 2001, 125, 7497

(13) For selected examples of phenoxyimine-coordinated catalyst, see: (a) Matsui, S.; Tohi, Y.; Mitani, M.; Saito, J.; Makio, H.; Tanaka, H.; Nitabaru, M.; Nakano, T.; Fujita, T. Chem. Lett. 1999, 1065. (b) Saito, J.; Mitani, M.; Mohri, J.; Yoshida, Y.; Matsui, S.; Ishii, S-I.; Kojoh, S.-I.; Kashiwa, N.; Fujita, T. Angew. Chem., Int. Ed. 2001, 40, 2918 (c) Ishii, S.; Mitani, M.; Saito, J.; Matsuura, S.; Kojoh, S.; Kashiwa, N.; Fujita, T. Chem. Lett. 2002, 23, 1118. (d) Mitani, M.; Nakano, T.; Fujita, T. Chem. Eur. J. 2003, 9, 2396.

(14) Stöber, W.; Fink, A.; Bohn, E. J. Colloid Interface Sci. 1968, 26, 62.

(15) Monteil, V.; Stumbaum, J.; Thomann, R.; Mecking, S. Macromolecules 2006, 39, 2056

(16) For examples of surface functionalization of silica particles with organosilanes see: (a) Philipse, A. P.; Vrij, A. J. Colloid Interface Sci. 1989, 128, 121. (b) Bourgeat-Lami, E.; Lang, J. J. Colloid. Interface Sci. 1998, 197, 293. (c) Beck, C.; Härtl, W.; Hemppelmann, R. Angew. Chem., Int. Ed. 1999, 38, 1297. (d) Tolnai, Gy.; Csempesz, F.; Kabai-Faix, M.; Kálmán, E.; Keresztes, Zs.; Kovács, A.; Ramsden, J. J.; HórvölgyiZ., Langmuir 2001, 17, 2683. (e) Bagwe, R. P.; Hilliard, L. R.; Weihong, T. Langmuir 2006, 22, 4357.

(17) The high graft density indicates the presence of cross-linked organosilanes on the silica surface. ${ }^{15,16 a, b}$
(18) Naundorf, C.; Matsui, S.; Saito, J.; Fujita, T.; Klapper, M.; Müllen, K. J. Polym. Sci., Part A: Polym. Chem. 2006, 44, 3103.

(19) Murphy, E. F.; Schmid, L.; Bürgi, T.; Macieejewesky, M.; Baiker, A.; Günther, D.; Schneider, M. Chem. Mater. 2001, 13, 1296.

(20) Mitani, M.; Mohri, J.; Yoshida, Y.; Saito, J.; Ishii, S.-I.; Tsuru, K.; Matsui, S.; Furuyama, R.; Nakano, T.; Tanaka, H.; Kojoh, S.-I.; Matsugi, T.; Kashiwa, N.; Fujita, T. J. Am. Chem. Soc. 2002, 124, 3327.

(21) (a) Phillips, R. A. J. Polym. Sci.: Part B: Polym. Phys. 1998, 36, 495. (b) Kresteva, M.; Nedkov, E.; Radilova, A. Colloid Polym. Sci. 1985, 263, 273. (c) Höhne, G. W. H. Polymer 2002, 43, 4689, and references therein. (d) Joo, Y. L.; Han, O. H.; Lee, H.-K.; Song, J. K. Polymer 2000, 41, 1355.

(22) (a) Farar, D. F.; Brain, A. A. Biomaterials 1997, 18, 1677. (b) Cook, J. T. E.; Klein, P. G.; Ward, I. M.; Brain, A. A.; Farar, D. F.; Rose, J. Polymer 2000, 41, 8615. (c) Debnath, S.; Ranade, R.; Wunder, S. L.; Baran, G. R.; Zhang, J.; Fisher, E. R. J. Appl. Polym. Sci. 2005, 96, 1564.

(23) (a) Badley, R. D.; Ford, W. T.; McEnroe, F. J.; Assink, R. A. Langmuir 1990, 6, 792. (b) Westcott, S. L.; Oldenburg, S. J.; Lee, T. R.; Halas, N. J. Langmuir 1998, 14, 5396. (c) Jelinek, L.; Dong, P.; Rojas-Pazos, C.; Taibi, H.; Kovats, E. Langmuir 1992, 8, 2152. (d) Van Blaaderen, A.; Vrij, A. J. Colloid Interface Sci. 1993, 156, 1. (e) Anderson, M. J.; Seery, T. A. P. J. Am. Chem. Soc. 2005, 127, 4416.

(24) Webb, P. A.; Orr, C. Analytical Methods in Fine Particle Technology; Micromeritics 1997, 55.

(25) Iler, R. K. The Chemistry of Silica; Wiley: New York, 1979; p 483.

(26) Van Helden, A. K.; Jansen, J. W.; Vrij, A. J. Colloid Interface Sci. 1981, 81, 354

(27) Conner, W. C.; Webb, S. W.; Spanne, P.; Jones, K. W. Macromolecules 1990, $23,4742$.

(28) Jang, Y.-J.; Naundorf, C.; Klapper, M.; Müllen, K. Macromol. Chem. Phys. 2005, 206, 2027.

(29) (a) Eberstein, C.; Garmatter, B.; Reichert, K.-H.; Sylvester, G. Chem. Ing. Tech. 1996, 68, 820. (b) Zöllner, K.; Reichert, K.-H. Chem. Ing. Tech. 2001, 73, 849. (c) Zöllner, K.; Reichert, K.-H. Chem. Eng. Technol. 2002, 25, 707. (d) Knoke, S.; Ferrari, D.; Tesche, B.; Fink, G. Angew. Chem., Int. Ed. 2003, 42, 5090 .

(30) (a) Zechlin, J.; Steinmetz, B.; Tesche, B.; Fink, G. Macromol. Chem. Phys. 2000, 201, 515. (b) Bonini, F.; Fraaije, V.; Fink, G. J. Polym. Sci., Part A: Polym. Chem. 1995, 33, 2393. (c) Knoke, S.; Korber, F.; Fink, G.; Tesche, B. Macromol. Chem. Phys. 2003, 204, 607.

(31) (a) Floyd, S.; Choi, K. Y.; Taylor, T. W.; Ray, W. H. J. Appl. Polym. Sci. 1986, 31, 2231. (b) Noristi, L.; Marchetti, E.; Baruzzi, G.; Sgarzi, P. J. Polym. Sci., Part A: Polym. Chem. 1994, 32, 3047. (c) Pater, J. T. M.; Weickert, G.; Loos, J.; Van Swaaij, W. P. M. Chem. Eng. Sci. 2001, 56, 4107.

(32) Cecchin, G.; Marchetti, E.; Baruzzi, G. Macromol. Chem. Phys. 2001, 202, 1987.

(33) Miller, A. O.; Furin, G. G. J. Fluor. Chem. 1987, 36, 247-272.

(34) Mikami, K.; Terada, M.; Nakai, T. J. Am. Chem. Soc. 1990, 112, 3949.

(35) Berendsen, G. E.; de Galan, L. J. Liq. Chromatogr. 1978, 1, 561.

MA801995G 